\title{
CHANGING TRENDS OF VAGINAL INFECTION
}

Padhye S M

\section{ABSTRACT}

\section{Introduction}

Vaginal discharge and /or infection are very distressing to all women.Vaginal infection encompasses-Vaginosis/ vaginitis,Trichomonal vaginitis and Monilial or fungal infection. Vaginal discharge could be due to foreign body such as ring pessary inserted for uterovaginal prolapse or for induction of abortion by untrained Dais in Nepal. It could be due to physiological condition, such as -during mid menstrual and pregnant state. A study of pattern of infection in vaginal discharge has been presented in this study.

\section{Objective}

To find the pattern of infection in the vaginal discharge of patients attending a private Gynae. Clinic.

\section{Material and method}

This is a prospective study done during the period, November 2001 to July 2002 with "Hanging drop method" of the discharge, collected from the vagina.

One thousand patients complaining of vaginal discharge with or without itching, burning sensation, pain in the lower abdomen and subfertility were enrolled in this study.

Age, parity, husband's occupation, family planning methods used, history of drugs intake and subfertility were expressed.

\section{Result}

It was found that Monilial infection 36.8\%,Monilial infectin with vaginitis was found in6.4\% Trichomonal infection $0.9 \%$, Trichomonas with vaginitis $1.3 \%$ and vaginitis to be $19.5 \%$.Thirtyfive percent had had no abnormality in the slide.There were 11 diabetic patients.Seventeen were having some or the other drugs during the study period. Seventyfour patients revisited for same complaints. Out of which 41 had no abnormalities.

The treatment given was, Clotrimazole $200 \mathrm{mg}$ daily locally for three days for 3 courses and Fluconazole $150 \mathrm{mg}$ orally single dose for Monilial infection. For trichomonal infection, Metronidazole $200 \mathrm{mg}$ three times on day was prescribed to both husband and wife. In case of Vaginitis, Doxycycline $100 \mathrm{mg}$ two times a day was advised. For pruritus,local application of Betamethasone was given.

\section{Conclusion}

It was noted that every third patient attending this clinic complained of vaginal discharge but $35 \%$ had no abnormality. By this study, the trend of vaginal infection seems to be changing.More Monilial than Trichomonal infection was found in these patients, in earlier studies the incidence of Trichomonal infection was getting less and Monilial infection is getting higher.

Key Words: Monilial infection, Trichomonas vaginitis, Non-specific vaginitis. 


\section{INTRODUCTION}

One in three women wants consultation for vaginal discharge. It is very difficult for a woman to get treatment for vaginal discharge/infection due to the lack of proper diagnosis in the outpatient department (OPD) in many hospitals of Nepal.

Instant examination of wet swab and proper treatment is not being performed in the OPD. The reason may be due to overload or the specimen sent to the laboratory is either dry or dried, or lost; if at all the report is ready, next day or so, the concerned doctor is not there when the woman brings the report because her/his OPD is on some other day. Therefore, in 1982 a small private clinic was started taking this into serious consideration, as this is a very distressing condition for a patient although not life-threatening. For every client complaining of vaginal discharge, a wet swab was taken from the cervical canal and / or from the posterior fornix or from the vaginal orifice and sent to the lab. And tested microscopically with a hanging drop method by a trained microscopist -Lab. assistant. It was assured that the result was made available within 10 minutes and treatment was started accordingly.

It is interesting to note that the pattern of vaginal infection is changing slowly and monilial infection is becoming more predominant at present than TV infection, which was more common a decade ago.

\section{OBJECTIVE}

To find the pattern of infection in the vaginal discharge of patients attending Gynaecology Clinic.

\section{MATERIAL AND METHOD}

This is a prospective study carried out in a private setting. The study was done during November 2001 to July 2002.

One-thound cases were studied who complained vaginal discharge.

Apart from the complaint of vaginal discharge, each woman was also asked whether she had itching/ irritation, Burning micturition, dyspareunia, lower abdominal pain or whether she had come for consultation for sub fertility.

Her name, age, parity, (Abortion excluded) husband's occupation, family planning method if any, history of drug taken within the week also were noted.

A general examination along with that of respiratory and cardiovascular was performed; abdomen was examined and palpated for any mass/ pregnancy or tenderness.
A Cusco's speculum of appropriate size was introduced according to the marital and/or parity status of the patient.

A sterile cotton swab in a stick was taken and the specimen of vaginal discharge collected from the posterior fornix and put in a sterile bottle.

In case of a small child or unmarried woman, a swab was taken from the vaginal orifice.

The swab was sent immediately to the path-lab. The labassistant was well-trained microscopist to find out whether the discharge contained Monilia- budding yeast, or moving protozoa-Trichomonas vaginalis (TV).

If there were plenty / moderate amount of pus cells- more than 1 per high power field, a note of it was also made and it was labelled as "Vaginitis."- Moderate or severe, depending upon the amount of pus cells.

If the vagina was found to be inflamed or copious pus like discharge was noted during clinical examination, a slide was prepared and sent for Gram's stain to look for Gram-negative diplococci. In case of severe vaginitis (diagnosed clinically) a swab was sent for culture and sensitivity test.

Culture for Candida and Trichomonal vaginalis was not done as the facilities did not exist.

\section{TREATMENT PLAN}

\section{Monilial infection}

Clotrimazole $200 \mathrm{mg}$ intrvaginally at bed time for three days, to be repeated for three courses and Fluconazole 200 mg orally single dose.These patients were asked to come after three months if needed.

Trichomonal infection-Metronidazole $200 \mathrm{mg}$ three times a day orally to both husband and wife for seven days. They were advised to come after a weak to see whether the infection was cured.

\section{Vaginitis}

Doxycycline $200 \mathrm{mg}$ daily for seven days, and to report if any trouble. If there is itching,local application of Betamethasone cream was advised.

All of these patients were advised not to use soap,detergents, synthetic underwear and the jean pants,and to take care about the personal hygiene. 


\section{RESULT}

During the study period, there were 1074 patients complaining of vaginal discharge. Seventy-four cases revisited with or without itching and / or irritation. The result of 1000 new patients were reported regarding the infection.

\section{Clinical presentation}

One hundred and forty six patients complained of itching vulva. Sixty of them complained of burning sensation at vulva or vagina during micturition. Sixteen of them c/o lower abdominal pain and dyspareaunia. One hundred and twenty six (12.6\%) patients reported for the treatment of sub fertility.

\section{Recurrence}

Seventy four patients re-visited the clinic for second time and one of them re- visited third time during the study period of whom Trichomonal infection $(n=22)$ were advised to return back after a course of metronidazole, but only ten of them came for follow up. Out of repeat visits, in 41 cases no abnormality was found. Twenty-four of them had Monilial infection, one had Trichomonal, and one case was having repeated Monilial infection on third visit. And the rest 7 were having vaginitis.

Most of the women attending for consultation for vaginal problems belonged to child- bearing age. The average age was found to be 31 years and median age, 33 years in the study group. The eldest woman was aged 83 and youngest was 9 years of age.

In eighteen cases without fungal or TV infection and six with Monilial infection and two cases with Trichomonal infection, the vagina appeared very much inflamed. Ninety-seven cases without Monilial or Trichomonal infection had studded with pus cells giving rise to vaginal infection. Sixty our cases with monilal and thirteen cases with Trichomonal infection had plenty of pus cells. Culture of the discharge done for four cases who had pouring pus from the vagina were reported as having no growth. None of the discharge had Gonococcus on Gram stain.

\section{Parity and contraception}

There were one hundred and twenty six (12.6\%) patients coming for the treatment of sub fertility .One hundred and seventy-seven $(18 \%)$ were nulli para. One hundred and forty-nine (14.9\%) had one child. Two hundred and sixty one $(26.1 \%)$ were para two.

One hundred and fifty (15.0\%) women were mothers of three children. One hundred and three $(10.3 \%)$ women had four children. Para 5+(One, Para 12) were 101 (10.1\%) average number of children to be 2.4 / couple.

Table I : Distribution of patients by Age group and type of infection

Table II : Distribution of cases according to the parity status and infection 
Table III : Distribution of 349 cases (35\%) of cases according to the method of contraception

One hundred and seventeen $(12 \%)$ had permanent sterilisation. Onehundred and three patient's spouse (10\%) had undergone vasectomy. Forty of them $(4 \%)$ were on Depot Provera; seventeen $(1.7 \%)$ were taking oral contraceptive pills. Thirtytwo $(3 \%)$ were using IUCD and Norplant users were found to be only 5 . (0.05\%). Fifty-five $(5.5 \%)$ reported to be using condoms thirty-four $(3.4 \%)$ were unmarried taken granted as not using contraception. Twenty-five were pregnant for first time during the study period, rest did not use any Contraceptive method .Out of 126 cases of sub fertility, 42 (33\%) had Monilial and four had TV infection and 17 had vaginitis.

It was found that $35 \%$ of cases used some or the other form of contraception in the study group.

\section{History of medication}

Thirty patients during the study period gave history of being on drug such as antibiotics and five of them were on hormones, which could have aggravated vaginal infection.One patient on antibiotics was having Monilial infection.Nine of the patiens were taking hormones for noncontraception purpose,two of these had Monilial infection.

One of the patients was found to have a foreign body in the vagina previously introduced outside somewhere to induce abortion, another two had ring pessary in situ for the prevention of utero- vaginal prolapse, and these two had vaginitis.

One woman, who had an unhealthy looking cervix, had an abnormal Papsmear. She underwent hysterectomy during the study period and the histopathological examination of the specimen revealed "Adenocarcinoma" of the cervix. During the study period, thirteen cases were found Diabetic out of which three had Monilial infection and others had normal report.

\section{Spouse}

There were 34 unmarried women out of which 15 had fungal infection 2 associated with vaginitis and two had non-specific vaginitis. (There were 45 pregnant among the study group. Nineteen pregnant women had fungal infection and no one had Trichomonal infection during pregnancy. There were 11 widow/separated from husband for years, seven of them had fungal infection and four had non-specific vaginitis).

In this study, there was none taking antibiotics. Most of them were in childbearing age, sexually active.

There is no custom of bubble bath or vaginal douching here. There is fermented food-taking habit of Nepalese people.

\section{DISCUSSION}

Present study showed that $43.2 \%$ of women complaining vaginal discharge are having Monilial infection, $19.5 \%$ are having non-specific Vaginitis, $2.2 \%$ are having TV infection and in the rest $35.1 \%$ no evidence of infection was found in the vaginal discharge.

Table IV : Comparision with other studies 
In 1982, there was only $0.80 \%$ of women were having Monilial infection and TV was found in $21.5 \%$ of cases. ${ }^{5}$

In a study published in 1993, TV was reported to be, $18.6 \%$ and Monilial infection, $8 \%{ }^{6}$

The present prospective study shows that there is increase in Monilial infection. The Trichomonal infection is decreasing.

Non-specific vaginitis is also quite high but detail study has not been carried out in this field.

It could be due to the fact that the women are using detergents, nylon panties and the food storing in the refrigerator is getting fashion nowadays giving rise to the Monilial infection.

Still serious is the recurrence of vulvovaginal candidiasis. Out of 74 cases who came back, ten had come for follow up for Trichomonal infection. One case was refractory to the treatment, one had developed monilial infection, and seven were cured of Trichomonal infection. Thirty patients with Monilial infection, turned up for follow up and eleven of them had persistant Monilial infection. Nineteen had normal report of vaginal discharge, though their symptoms were not relieved.

Observation has revealed that those who are having recurrent vulvo-vaginal candidiasis (RVVC), are found to be taking fermented green vegetables called GUNDRUK, fermented bamboo-shoot, TAMA and fermented small fish called SIDRA etc.

\section{CONCLUSION}

The problem seems small but for the sufferer it is a matter of immense physical suffering, psychosexual problems, which may require instant attention, which is lacking in most of the hospitals and clinics.

It does not need much investment but need commitment so that same team of Doctors along with laboratory assistant see the case and follow her up to make the life easy for the patients.

This study reavels that there is changing trend of not only vaginal infection but also the management, i.e., previously Clotrimazole and Fluconazole were not available in this country for the treatment of Monilial infection.

\section{ACKNOWLEDGEMENT}

I am thankful to all my patients who took part in this study. I am also very much thankful to Mr. Uttam Charan Shrestha and Gyani Shrestha for helping me to carry out this work, unless their help it would not have been possible to do this so called minor problem but very important problem of the women of Nepal.

\section{REFERENCES}

1. Stephen Higgins. Management of recurrent vulvovaginal candidiasis. The Obstetretician \&Gynaecologist2001; vol 3, no 4: $184-188$

2. Nyirjesy, Paul et al. "Chronic Focal vaginitis: The value of Cultures."AmericanJ ournal of Obstetricians \& Gynecology 173, no. 3, part 1 (September 1995): 820-3.

3. Betty A Forbes, Raniel et al Genital tract infection: Bailey \& Scott's Diagnostic Microbiology (10 ${ }^{\text {th }}$ ed) 1998. 363-379.

4. David E Soper, Novak's Gynaecology $12^{\text {th }}$ edition. Edited by J onathaS. Berek, (199“Genitourinary Infections \&Sexually transmitted Diseases" 429-445.

5. Padhye, Saraswat, "A Profile of Vaginal Discharge"J NMA Vol. 20. No 3. J uly-Sept(1982).

6. Padhye. S. “Trichomonal vaginaisl infection in Nepalese women in private clinic". J . Inst. Med., 1993, 15. 290-293.

7. Wadhwa etal. "Candid-B Creamin the TreatmentofCandidiasis with Inflammatory Dematoses-National Study Group"J IMA Vol.98 No. 9. Sept. 2000. (ISSN 0019- 5847)

8. David Mabey, et al "Rapid diagnostic tests for sexually transmitted infection"IPPF Medical Bulletin Vol.36 No. 3J une 2002 (ISSN 0019-0357).

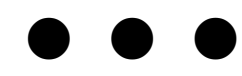

